"This is the peer reviewed version of the following article: [Journal of Futures Markets Volume 36, Issue 2, pages 127-152, February 2016], which has been published in final form at [http://dx.doi.org/10.1002/fut.21717]. This article may be used for non-commercial purposes in accordance with Wiley Terms and Conditions for Self-Archiving." 


\title{
The return-volatility relation in commodity futures markets
}

\author{
Carl Chiarella ${ }^{\mathrm{a}}$, Boda Kang ${ }^{\mathrm{b}}$, Christina Sklibosios Nikitopoulos ${ }^{\mathrm{a}, *}$, Thuy-Duong Tô $^{\mathrm{c}}$ \\ ${ }^{a}$ University of Technology, Sydney, \\ Finance Discipline Group, UTS Business School, \\ PO Box 123 Broadway NSW 2007, Australia \\ ${ }^{b}$ University of York, \\ Department of Mathematics, \\ Heslington, York YO10 5DD, United Kingdom \\ ${ }^{c}$ The University of New South Wales, \\ UNSW Business School, School of Banking and Finance \\ Sydney NSW 2052, Australia
}

\begin{abstract}
By employing a continuous time multi-factor stochastic volatility model, the dynamic relation between returns and volatility in the commodity futures markets is analysed. The model is estimated by using an extensive database of gold and crude oil futures and futures options. A positive relation in the gold futures market and a negative relation in the crude oil futures market subsist, especially over periods of high volatility principally driven by market-wide shocks. The opposite relation holds over quiet periods typically driven by commodity-specific effects. According to the proposed convenience yield effect, normal (inverted) commodity futures markets entail a negative (positive) relation.
\end{abstract}

Keywords: Return-volatility relation; Commodity futures returns; Gold futures volatility; Crude oil futures volatility; Normal futures markets; Inverted futures markets;

JEL: G13, E32, Q40

\footnotetext{
The authors would like to thank an anonymous reviewer and the editor Robert Webb for valuable comments. Thanks are also extended to seminar participants at the 2014 Bachelier Finance Society World Congress, the 2014 Conference on the Performance of Financial Markets and Credit Derivatives, the FIRN 2013 conference and the UTS Finance Discipline Group internal research seminars for fruitful discussions and helpful suggestions. Financial support from the Australian Research Council is also acknowledged (DP 1095177, The Modelling and Estimation of Volatility in Energy Markets).

约 Professor Carl Chiarella, Dr Boda Kang, Dr Christina Sklibosios Nikitopoulos and Dr Thuy-Duong Tô.

*Correspondence author, Finance Discipline Group, UTS Business School, University of Technology, Sydney, PO Box 123 Broadway NSW 2007, Australia. Tel: +61 29514 7768, Fax: +61 29514 7722, e-mail: christina.nikitopoulos@uts.edu.au
} 


\section{Introduction}

One of the fundamental measures to analyze the behavior and the attribute of financial markets is the nature of the relation between returns and innovations in volatility. As nowadays commodity derivatives play a vital role in investment and risk management, a comprehensive understanding of the relation between price returns and volatility changes in commodity futures markets is of critical importance.

Asymmetric volatility is a well known empirical phenomenon in equity markets describing the negative relation between stock returns and stock return (conditional) volatility with the effect being more robust during periods of market crashes where high volatility is combined with low returns. An extensive literature has been dedicated to explain this relation. The two main accounts put forward are the leverage effect postulated by Black (1976b) and the volatility feedback effect proposed by Campbell and Hentschel (1992), while more recently, a new explanation via the behavioral effect has been introduced by Hibbert, Daigler and Dupoyet (2008). ${ }^{1}$ The return-volatility relation has also been studied in the commodity markets. The empirical phenomenon of a positive return-volatility relation (referred to as inverted asymmetric volatility) in commodity markets has been explained by $\mathrm{Ng}$ and Pirrong (1994) via the inventory effect that is linked to the theory of storage. Tully and Lucey (2007) and Baur (2012) study the return-volatility relation in the gold market and use the safe haven property of gold to explain the prevailed positive relation. Hassan (2011) and Salisu and Fasanya (2013) have found a negative return-volatility relation in the crude oil market while Carpantier and Samkharadze (2013) demonstrated the importance of accommodating the asymmetric volatility feature in commodity hedging strategies. However, most of these studies are based on GARCH models that preserve the limitation of allowing only for $\mathrm{V}$ or $\mathrm{U}$ shaped volatility reactions (as they restrict volatility to be a deterministic function of

\footnotetext{
${ }^{1}$ The leverage effect implies that negative stock return shocks cause an increase in volatility due to the increase in the firm's leverage. A similar reaction in the commodity market is also termed as the leverage effect, where negative futures (or spot) return shocks tend to increase volatility. The volatility feedback effect suggests that any change in volatility, but in particular an increase in volatility, will decrease stock returns. Alternatively based on the behavioral concepts of representativeness, affect and extrapolation bias, individuals prefer positions of high return and low risk as these represent a good investment.
} 
the return shock). Moreover, these models investigate the relation only in spot commodity markets as they cannot model sufficiently the entire volatility term structure of futures returns. Nevertheless, as futures prices emerge with greater transparency (compared to spot commodity prices, which depend heavily on grade and location), an analysis of futures prices would provide a more comprehensive understanding of the nature of the relation between the price dynamics in commodity markets and their volatility.

The key contribution of this paper is that it provides both a qualitative and a quantitative analysis of the return-volatility relation in commodity futures markets by using a stochastic volatility model within the Heath, Jarrow and Morton (1992) framework. The proposed continuous time model is well suited to analyze and measure the entire term structure of the commodity futures return volatility. It accommodates multiple volatility factors with flexible volatility term structures ranging from exponentially decaying to hump-shaped. Moreover, the volatility factors feature the empirically observed characteristics of unspanned components in commodity futures volatility (Trolle and Schwartz (2009)) and potential asymmetries in the dynamics of the volatility, (Ng and Pirrong (1994)). These two features can be captured by the correlation between the innovations of the futures price returns and the innovations of its volatility.

The proposed stochastic volatility model possesses finite-dimensional affine realizations for commodity futures prices and quasi-analytical prices for options on commodity futures. Subsequently, the model is estimated by fitting to both futures prices and options prices. An extensive database of daily futures and option prices extending to 31 years for gold and 21 years for crude oil is used. Thus, the estimated models integrate information from both futures prices and options prices that guarantee a better fit to the observable futures term structure as well as the (implied) volatility term structure. Existing literature on the return-volatility relation estimates volatility by using either sample return variances or implied volatilities, see for instance Dennis, Mayhew and Stivers (2006) for a study in equity markets. There is limited literature that takes into account both futures prices and option prices.

The gold futures market and the crude oil futures market were considered in the analysis for several reasons. Both markets are amongst the most liquid commodity derivatives mar- 
kets that impact, and are influenced by, macro-economic and financial conditions, as they are used widely for investment purposes and/or hedging and speculation. Moreover, gold is classified as an investment commodity whereas crude oil as a consumption commodity. Since these two markets are fundamentally different, the study provides insightful findings of the nature of the return-volatility relation in these two distinct futures markets. To enhance the analysis and verify the significance of different volatility market conditions, the models are estimated over the whole period (as it has been done in most literature) as well as over smaller subsamples differentiated by their volatility intensity.

The study not only identifies the nature of the return-volatility relation but also provides a justification of the results, by using long-established theories and hypotheses such as the volatility feedback effect, the safe haven property and the theory of storage. Based on our empirical results, during volatile periods which are typically driven by market-wide shocks, the gold futures return-volatility relation is positive as it can be explained by the safe haven property of gold. However, during less volatile market conditions, a negative relation in the gold futures market is present indicating that gold futures respond similarly to financial assets like equities (for instance, the volatility feedback effect is present). Conversely, during high volatility periods, the crude oil futures return-volatility relation is negative, while during low volatility periods the relation in the crude oil futures market becomes positive, as explained by the inventory effect. To explain the crude oil futures volatility reaction, a new account emerges, the so called convenience yield effect. This effect is more general compared to the inventory effect as it can account for non-fundamental changes of futures prices apart from the associated fundamental changes such as inventory. Based on the empirical results for crude oil, one of the key findings is that normal (inverted) ${ }^{2}$ consumption commodity markets are characterised by a negative (positive) return-volatility relation. Consequently, the return-volatility relation can be linked to the convenience yield of the commodity.

It is further illustrated that for these two commodity futures markets, when the market uncertainty is high, the potential market-wide shock effects dominate, while when the market

\footnotetext{
${ }^{2} \mathrm{~A}$ futures market is normal (inverted) when futures prices of near maturities trade lower (higher) than futures prices of distant maturities, leading to an upward-sloping (downward-sloping) forward curve.
} 
is quiet the commodity-specific shock effects dominate. This is consistent with the finding of Dennis et al. (2006) who have shown that asymmetric (implied) equity volatility is primarily attributed to systematic market-wide factors rather than aggregated firm-level effects. The paper also confirms that the relation is consistent with the option-derived implied volatility skew.

The remaining of the paper is organized as follows. Section 2 discusses the relation of futures returns and volatility for the two distinct types of commodity markets, namely investment commodities and consumption commodities. Section 3 presents a generalised stochastic volatility model and introduces an empirical tool to analyse the return-volatility relation in commodity futures markets. Section 4 describes and analyzes the data of gold and crude oil derivatives and explains the method employed to estimate the proposed model. Section 5 presents the estimation results and reflections on the return-volatility relation. Section 6 concludes.

\section{The relation between returns and volatility in commodity futures markets}

This section discusses the features of the return-volatility relation in commodity futures markets in terms of the differences between investment commodities and consumption commodities. For each commodity, the spot prices as well as the futures prices are determined by regular supply and demand forces driven by commodity specific fundamentals such as inventories, production and consumption. Apart from the regular supply and demand forces, commodity derivative prices, returns and volatility are also affected by market-wide shock factors such as investment growth, interest rates, exchange rates, market contractions and weather. Consequently, we argue that the relation between futures price returns and volatility is influenced by two main sources, namely, commodity-specific effects and market-wide shock effects. These two effects impact differently the two distinctive commodity markets, namely, investment commodities and consumption commodities. These effects are further confirmed in Section 5 for the gold futures market and the crude oil futures market. 


\subsection{Investment commodities}

Investment commodities such as the monetary metals gold and silver are treated by the majority of the market participants as financial assets. In the leading financial market, the equity market, there is compelling empirical evidence that the volatility feedback effect and/or the leverage effect typically generates an asymmetric volatility reaction. For investment commodities accordingly, a similar volatility reaction should prevail where falling commodity price returns are associated with an increase in conditional volatility. As the spot commodity price returns are historically positively correlated to the futures price returns (for instance for gold, the correlation coefficient between the 12-month futures returns and 1-month futures returns over thirty years is 0.991 ), this effect can be transmitted to the futures prices, implying that increasing futures price volatility is associated with negative futures price returns. Additionally, if a volatility shock is anticipated then futures traders are not willing to trade, thus futures prices drop to balance buying and selling volumes. Thus negative futures return shocks are associated with increasing volatility. Overall due to commodity specific effects, for investment commodities, a negative relation between futures price returns and volatility should be pertinent.

Alternatively, most investment commodities, such as gold, have the property of a safe haven investment. That is, investment commodities are sought by investors during periods of uncertainty driven by market-wide shocks, see Baur and McDermott (2010) and Reboredo (2013). Positive commodity price changes that are principally associated with safe haven purchases, are signals for increasing risk or uncertainty in macroeconomic and financial conditions. This introduces uncertainty in the market, thus increasing volatility. This effect is consistent with the empirical studies of Giamouridis and Tamvakis (2001) and Baur (2012) in the gold market. Subsequently, as futures commodity prices are historically positively correlated with spot commodity prices, the same reaction would be anticipated in the futures markets. Apart from the safe haven property, according to the Market Pressure Theory (Cootner (1960)), while futures prices increase, large long speculative trading activity in futures markets would be taken that will lead to further futures price increases enforcing a positive return-volatility relation. Additionally, the connection between inventory and volatility (as low inventory signals high future volatility) can also potentially produce inverted 
asymmetries in futures volatility.

\subsection{Consumption commodities}

For consumption commodities, such as the crude oil, supply and demand forces primarily affect the market via inventory. As explained by $\mathrm{Ng}$ and Pirrong (1994), in accordance to the Theory of Storage, the inventory effect implies that a low inventory (among other reasons due to a shortage in the commodity) will drive commodity prices to rise and the market volatility to increase and vice versa. Carpantier and Dufays (2013) have confirmed that the inventory effect is generally significant for a variety of commodities, especially when the unconditional variance is time-varying. Inventory and convenience yield, according to the Theory of Storage (Kaldor (1939)), are negatively correlated. Pindyck (2001) explains that as volatility increases, the convenience yield increases as a result of an increasing demand for storage; market participants will increase their inventories in order to absorb the anticipated shocks in production and consumption. This drives the commodity spot price to rise more than futures prices, leading to an inverted futures market (which is a typical market condition for consumption commodities especially over commodity scarcity periods). At the same time, the higher the convenience yield, the stronger the pressure for a rise in, preliminarily, the spot and subsequently the futures commodity prices is anticipated. The volatility of the spot price returns, the volatility of the futures price returns and the volatility of the convenience yield are also all increasing. Thus positive futures return shocks are associated with increasing volatility. However, if inventory is high, the convenience yield is relatively low, commodity prices tend to decrease and the volatility is getting lower, reflecting the decreasing risk of the exhaustion of inventories. Hence negative return shocks would signal lower future volatility. Overall for consumption commodities, due to commodity specific effects including the inventory effect, a positive relation between futures price returns and volatility should be pertinent.

The impact of severe market-wide shocks on the futures prices of consumption commodities and consequently the return-volatility relation is not always definite and straightforward. ${ }^{3}$ In the last decade, as a result of the 9/11 terrorist attacks, the US invasion to Iraq

\footnotetext{
${ }^{3}$ Note that, all consumption commodities do not have the same reactions to extreme market conditions of
} 
and Global Financial Crisis (GFC), see Kilian (2009) and Tokic (2010), the crude oil market has experienced excessive volatility, not only in terms of volatility of spot prices and futures price returns but also in terms of volatility of adjusted spreads (adjusted spreads are considered as a measure of convenience yield, see Geman and Ohana (2009)). The 2008 oil bubble was attributed to the increasing oil demand amidst stagnant oil production to meet the strong global economic growth that occurred up to 2008, see Kilian and Hicks (2013), as well as increasing speculative trading activity. ${ }^{4}$ These factors have been causing oil prices to rise until mid of 2008 where intense economic contraction led by the GFC caused oil prices to plunge by $80 \%$ between July 2008 and December 2008. While the increasing volatility was predominantly attributed to economic contractions that impacted negatively on the demand for crude oil, that led to a noticeable decrease of the spot and futures commodity prices and returns (as observed in the second half of 2008) implying a negative return-volatility relation and a considerable decrease of the convenience yield. ${ }^{5}$ Thus the considerably lower (mostly negative) convenience yield was reflected by the persistence of normal market conditions in these markets. Traditionally inverted consumption commodity markets were normal and more specifically, the crude oil market underwent an extended period of normal market conditions over the last four years following the economic contraction of the GFC. ${ }^{6}$ This reverse flow of risk premium may be the result of financial investors seeking portfolio diversification (Hamilton and Wu (2014)) or speculative behaviour (as normal market conditions are gener-

extensive volatility. For instance as a result of the significant market-wide shock of the GFC, the traditionally inverted crude oil market has been normal for an extended period of 4 years, while the sugar futures market was strongly inverted. The fall of sugar production in 2009-2010 due to poor weather conditions in major production areas combined with the scarcity of investment capital to increase production as a result of the GFC and an increasing demand for sugar from food industries have led to a very strong convenience yield.

${ }^{4}$ Increasing liquidity attributed to the price discovery in futures markets has the effect of relating positive returns with decreasing volatility (the liquidity effect). Note that non-fundamental changes to futures prices typically are transmitted to spot prices even without inventories adjustments, see Morana (2013).

${ }^{5}$ This is not consistent with the fundamentals of consumption commodities as presented in Pindyck (2001), where under increasing volatile market conditions, the convenience yield increases as a result of an increasing demand for storage.

${ }^{6}$ It is worth noticing that the Asian financial crisis in 1997-1998 caused a similar extended period of normal market conditions that lasted for approximately one and half years. 
ally associated with a high level of volatility, see Gorton, Hayashi and Rouwenhorst (2013), or implying a structural shift in inventory management, see Morana (2013)).

In light of the above observations, a new effect emerges that has explanatory power on the return-volatility relation in futures commodity markets and it is referred to as the convenience yield effect. This effect is more relevant to consumption commodities. According to this effect, as convenience yield increases (decreases) implying that the commodity market becomes inverted (normal), then the increasing volatility associated with the shocks effecting the convenience yield leads to increasing (decreasing) futures returns resulting from the upward (downward) pressure in the spot commodity prices. Thus inverted commodity futures markets should entail a positive return-volatility relation, while normal commodity futures markets give rise to a negative return-volatility relation. Note that the convenience yield effect is more general compared to the inventory effect as it can account for non-fundamental changes of futures prices. Section 5.2 demonstrates that this effect can explain the returnvolatility relation especially in the crude oil market.

\section{Modelling the return-volatility relation}

\subsection{A stochastic volatility model for commodity futures prices}

Let $\mathbf{V}=\left\{\mathbf{V}_{\mathbf{t}}, t \in[0, T],\right\}$ denote a stochastic volatility process describing the uncertainty in the commodity futures market and $F\left(t, T, \mathbf{V}_{\mathbf{t}}\right)$ denote the futures price, at time $t \geq 0$, of a commodity futures contract with maturity $T$ (for all maturities $T \geq t$ ). The spot price at time $t$ of the underlying commodity, denoted as $S\left(t, \mathbf{V}_{\mathbf{t}}\right)$ satisfies the relationship $S\left(t, \mathbf{V}_{\mathbf{t}}\right)=F\left(t, t, \mathbf{V}_{\mathbf{t}}\right), t \in[0, T]$. It is well known that the commodity futures price process can be described by a driftless stochastic process under a risk-neutral probability measure $Q$, since the futures price process is equal to the expected future commodity spot price under this measure, see Duffie (2001). Thus the risk-neutral dynamics of the futures price can be 
modelled as ${ }^{7}$

$$
\begin{aligned}
\frac{d F\left(t, T, \mathbf{V}_{\mathbf{t}}\right)}{F\left(t, T, \mathbf{V}_{\mathbf{t}}\right)} & =\sum_{i=1}^{n}\left(\kappa_{0 i}+\kappa_{i}(T-t)\right) e^{-\eta_{i}(T-t)} \sqrt{\mathbf{V}_{\mathbf{t}}^{\mathbf{i}}} d W_{i}^{1}(t), \\
d \mathbf{V}_{\mathbf{t}}^{\mathbf{i}} & =\mu_{i}^{V}\left(\nu_{i}^{V}-\mathbf{V}_{\mathbf{t}}^{\mathbf{i}}\right) d t+\varepsilon_{i}^{V} \sqrt{\mathbf{V}_{\mathbf{t}}^{\mathbf{i}}}\left(\rho_{i} d W_{i}^{1}(t)+\sqrt{1-\rho_{i}^{2}} d W_{i}^{2}(t)\right),
\end{aligned}
$$

where, $\mathbf{V}_{\mathbf{t}}=\left\{\mathbf{V}_{\mathbf{t}}^{1}, \ldots, \mathbf{V}_{\mathbf{t}}^{\mathbf{n}}\right\}$ is an $n$-dimensional process, $W^{1}(t)=\left\{W_{1}^{1}(t), \ldots, W_{n}^{1}(t)\right\}$ and $W^{2}(t)=\left\{W_{1}^{2}(t), \ldots, W_{n}^{2}(t)\right\}$, for all $t \in[0, T]$, denote independent standard Wiener processes under the risk-neutral probability measure and for $i=1, \ldots, n$, the parameters $\kappa_{0 i}$, $\kappa_{i}, \eta_{i}, \mu_{i}^{V}, \nu_{i}^{V}, \varepsilon_{i}^{V}$ and $\rho_{i}$ are constants. These model specifications allow for a variety of shapes for the volatility structure of futures prices, including exponentially decaying and hump-shaped volatility structures. There is empirical evidence that these are typical volatility structures of commodity futures return volatility, see Trolle and Schwartz (2009) and Chiarella, Kang, Nikitopoulos and Tô (2013).

The commodity forward price model (1) and (2) admits finite dimensional realisations, see Chiarella and Kwon (2003) and Björk, Landén and Svensson (2004) and leads to exponentially affine structures for the futures price process as the following proposition presents.

Proposition 1. The futures price $F\left(t, T, \mathbf{V}_{\mathbf{t}}\right)$ at time $t$ of a commodity futures contract with maturity $T$ is exponentially affine and can be expressed as

$$
\begin{aligned}
& F\left(t, T, \mathbf{V}_{\mathbf{t}}\right)=F\left(0, T, V_{0}\right) \exp \{-Z(t, T)\} \\
& Z(t, T)=\sum_{i=1}^{n}\left(\frac{1}{2}\left(\gamma_{i 1}(T-t) x_{i}(t)+\gamma_{i 2}(T-t) y_{i}(t)+\gamma_{i 3}(T-t) z_{i}(t)\right)+\left(\beta_{i 1}(T-t) \phi_{i}(t)+\beta_{i 2}(T-t) \psi_{i}(t)\right)\right),
\end{aligned}
$$

where for $i=1,2, \ldots, n$

$$
\begin{aligned}
& \beta_{i 1}(T-t)=\left(\kappa_{0 i}+\kappa_{i}(T-t)\right) e^{-\eta_{i}(T-t)}, \\
& \beta_{i 2}(T-t)=\kappa_{i} e^{-\eta_{i}(T-t)}, \\
& \gamma_{i 1}(T-t)=\left(\beta_{i 1}(T-t)\right)^{2} \\
& \gamma_{i 2}(T-t)=2 \beta_{i 1}(T-t) \beta_{i 2}(T-t), \\
& \gamma_{i 3}(T-t)=\left(\beta_{i 2}(T-t)\right)^{2} .
\end{aligned}
$$

\footnotetext{
${ }^{7}$ A suitable filtered probability space $\left(\Omega, \mathcal{A}_{T}, \underline{\mathcal{A}}, P\right), T \in(0, \infty)$ is considered and the required processes are $\underline{\mathcal{A}}$-adapted bounded with regular and predictable drifts and diffusions thus unique strong solutions for the associated SDEs exist.
} 
The state variables $x_{i}(t), y_{i}(t), z_{i}(t), \phi_{i}(t)$ and $\psi_{i}(t), i=1,2, \ldots, n$ satisfy the stochastic differential equations

$$
\begin{aligned}
d x_{i}(t) & =\left(-2 \eta_{i} x_{i}(t)+\mathbf{V}_{\mathbf{t}}^{\mathbf{i}}\right) d t, \\
d y_{i}(t) & =\left(-2 \eta_{i} y_{i}(t)+x_{i}(t)\right) d t, \\
d z_{i}(t) & =\left(-2 \eta_{i} z_{i}(t)+2 y_{i}(t)\right) d t, \\
d \phi_{i}(t) & =-\eta_{i} \phi_{i}(t) d t+\sqrt{\mathbf{V}_{\mathbf{t}}^{\mathbf{i}}} d W_{i}(t), \\
d \psi_{i}(t) & =\left(-\eta_{i} \psi_{i}(t)+\phi_{i}(t)\right) d t,
\end{aligned}
$$

subject to the initial conditions $x_{i}(0)=y_{i}(0)=z_{i}(0)=\phi_{i}(0)=\psi_{i}(0)=0$, with the volatility processes $\mathbf{V}_{\mathbf{t}}^{\mathbf{i}}$ following the dynamics (2).

Proof: Follows along the lines of Chiarella et al. (2013).

Duffie, Pan and Singleton (2000) and Collin-Dufresne and Goldstein (2002) have derived quasi-analytical solutions for European options on assets with their dynamics being characterized by exponentially affine models. Chiarella et al. (2013) have adjusted these results and have shown that under the commodity forward price model specifications (1) and (2), quasi-analytical prices for European options on futures contracts can be obtained, which are used in our empirical analysis. For the sake of completeness, Appendix A presents the European option pricing equations.

In addition, according to Dai and Singleton (2000) and Doran and Ronn (2008), the market price of futures price risk and the market price of volatility risk can be respectively specified by the "complete" affine representation

$$
\begin{gathered}
d W_{i}^{\mathbb{P}}(t)=d W_{i}^{1}(t)-\lambda_{i} \sqrt{\mathbf{V}_{\mathbf{t}}^{\mathbf{i}}} d t, \\
d W_{i}^{\mathbb{P} V}(t)=d W_{i}^{V}(t)-\lambda_{i}^{V} \sqrt{\mathbf{V}_{\mathbf{t}}^{\mathbf{i}}} d t,
\end{gathered}
$$

for $i=1, \ldots, n$, where $\lambda_{i}$ and $\lambda_{i}^{V}$ are constants, $d W_{i}^{V}(t)=\rho_{i} d W_{i}^{1}(t)+\sqrt{1-\rho_{i}^{2}} d W_{i}^{2}(t)$ and, $W_{i}^{\mathbb{P}}(t)$ and $W_{i}^{\mathbb{P} V}(t)$ are Wiener processes under the physical measure $\mathbb{P}$.

Note that, the correlation structure $\rho_{i}$ of the innovations driving the futures return process and the volatility process provides an indication of the level of volatility risk that can be hedged by futures contracts. For instance, when the Wiener processes are perfectly correlated, i.e. $\rho_{i}=1$ for all $i$, then portfolios of futures contracts can completely hedge the 
associated volatility risk. Otherwise, the volatility risk can be partially spanned by futures contracts alone. However, the correlation structure of the proposed stochastic volatility model is also linked to the return-volatility relation of commodity futures prices as the next section explains.

\subsection{Assessing the return-volatility relation}

Engle and Ng (1993) introduced the News Impact Function (NIF hereafter) as an empirical tool to analyse the return-volatility relation. Conditioning on the information available up to time $t$, the NIF measures the impact of the return shocks at time $t$, denoted as $\delta_{t}$, on the future volatility $\sigma^{2}(t+1, T)$ at time $t+1$. Typically, ARCH type models have been employed in the literature to study this relation, see for example the asymmetric ARCH models discussed in Glosten, Jagannathan and Runkle (1993) and Baur (2012).

However this definition cannot be applied directly to stochastic volatility models, where two sources of uncertainty are present at time $t$, namely the return shocks $\delta_{t}$ and the volatility shocks, denoted as $\epsilon_{t}$. For stochastic volatility models, the NIF should be generalised to account for its stochastic nature. Thus, the generalised NIF measures the impact of the return shocks $\delta_{t}$ at time $t$ on the expected future volatility $\mathbb{E}\left[\sigma^{2}(t+1, T)\right]$ at time $t+1$ (when conditioning on the information available up to time $t$ ). To compute the generalised NIF, the information available up to time $t$ is set to be constant, thus lagged volatility is fixed at the long run mean of $\sigma^{2}(t, T)$, denoted as $\bar{\sigma}^{2}$. Thus the generalised NIF is defined as

$$
N I F\left(\delta_{t}\right)=\mathbb{E}\left[\sigma^{2}(t+1, T) \mid \delta_{t}, \sigma^{2}(t, T)=\bar{\sigma}^{2}, \sigma^{2}(t-1, T)=\bar{\sigma}^{2}, \ldots\right],
$$

and, accordingly for the multi-dimensional case of model (1), it can be defined as

$$
N I F\left(\delta_{i t}\right)=\mathbb{E}\left[\sigma_{i}^{2}(t+1, T) \mid \delta_{i t}, \sigma_{i}^{2}(t, T)=\bar{\sigma}_{i}^{2}, \sigma_{i}^{2}(t-1, T)=\bar{\sigma}_{i}^{2}, \ldots\right]
$$

where $\bar{\sigma}_{i}^{2}$ are constants for $i=1,2, \ldots, n$ and $\delta_{i t}$ is the return shocks at time $t$ of the corresponding factor $i$.

Proposition 2. The NIF for the stochastic volatility model (1) and (2) can be expressed as

$$
N I F\left(\delta_{i t}\right)=\varphi_{i}^{2}(t+1, T)\left[\mu_{i}^{V} \nu_{i}^{V} \Delta t+\left(1-\mu_{i}^{V} \Delta t\right) \bar{V}_{t}^{i}+\rho_{i} \varepsilon_{i}^{V} \sqrt{\bar{V}_{t}^{i}} \delta_{i t}\right],
$$

where $\bar{V}_{t}^{i}=\bar{\sigma}_{i}^{2} / \varphi_{i}^{2}(t, T)$ and $\varphi_{i}(t, T)=\left(\kappa_{0 i}+\kappa_{i}(T-t)\right) e^{-\eta_{i}(T-t)}$. 
Proof: Let $R_{F}(t, T)$ denote the returns of the futures price of futures contracts with maturity $T$, then according to (1), returns can be expressed as

$$
R_{F}(t, T)=\sum_{i=1}^{n} \sigma_{i}\left(t, T, \mathbf{V}_{\mathbf{t}}\right) d W_{i}^{1}(t)
$$

where, by using the time deterministic functions $\varphi_{i}(t, T)$,

$$
\begin{aligned}
\sigma_{i}\left(t, T, \mathbf{V}_{\mathbf{t}}\right) & =\left(\kappa_{0 i}+\kappa_{i}(T-t)\right) e^{-\eta_{i}(T-t)} \sqrt{\mathbf{V}_{\mathbf{t}}^{\mathbf{i}}} \\
& =\varphi_{i}(t, T) \sqrt{\mathbf{V}_{\mathbf{t}}^{\mathbf{i}}} .
\end{aligned}
$$

An Euler approximation of the stochastic volatility process (2) provides the relation ${ }^{8}$

$$
\mathbf{V}_{\mathbf{t}+\mathbf{1}}^{\mathbf{i}} \approx \mu_{i}^{V} \nu_{i}^{V} \Delta t+\left(1-\mu_{i}^{V} \Delta t\right) \mathbf{V}_{\mathbf{t}}^{\mathbf{i}}+\varepsilon_{i}^{V} \sqrt{\mathbf{V}_{\mathbf{t}}^{\mathbf{i}}} \epsilon_{i t}
$$

where the volatility shocks $\epsilon_{i t}$ of the volatility factor $i$ and the return shocks $\delta_{i t}$ are iid $N(0,1)$ with correlation structure $\operatorname{corr}\left(\epsilon_{i t}, \delta_{i t}\right)=\rho_{i}$. By using (12) and (13) and fixing information at time $t$ or earlier at the constant long run volatility $\bar{\sigma}_{i}^{2}$, the generalised NIF (9) can be evaluated as follows

$$
\begin{aligned}
N I F\left(\delta_{i t}\right) & =\mathbb{E}\left[\sigma_{i}^{2}\left(t+1, T, \mathbf{V}_{\mathbf{t}+\mathbf{1}}\right) \mid \delta_{i t}, \sigma_{i}^{2}\left(t, T, \mathbf{V}_{\mathbf{t}}\right)=\bar{\sigma}_{i}^{2}, \sigma_{i}^{2}\left(t-1, T, \mathbf{V}_{\mathbf{t}-\mathbf{1}}\right)=\bar{\sigma}_{i}^{2}, \ldots\right] \\
& =\varphi_{i}^{2}(t+1, T) \mathbb{E}\left[\mathbf{V}_{\mathbf{t}+\mathbf{1}}^{\mathbf{i}} \mid \delta_{i t}, \mathbf{V}_{\mathbf{t}}^{\mathbf{i}}=\bar{V}_{t}^{i}, \mathbf{V}_{\mathbf{t}-\mathbf{1}}^{\mathbf{i}}=\bar{V}_{t-1}^{i}, \ldots\right] \\
& =\varphi_{i}^{2}(t+1, T)\left[\mu_{i}^{V} \nu_{i}^{V} \Delta t+\left(1-\mu_{i}^{V} \Delta t\right) \bar{V}_{t}^{i}+\rho_{i} \varepsilon_{i}^{V} \sqrt{\bar{V}^{i}} \delta_{i t}\right]
\end{aligned}
$$

which derives the result.

The slope of the NIF identifies the return-volatility relation. It is evident from equation (14) that the slope of the NIF depends on the correlation coefficient $\rho_{i}$, thus the returnvolatility relation can be assessed through the correlation coefficient $\rho_{i}$. A negative $\rho_{i}$ leads

\footnotetext{
${ }^{8}$ The stochastic volatility process used here is the process with the correlated Wiener processes $W_{i}^{1}(t)$ and $W_{i}^{V}(t)$, such that,

$$
d \mathbf{V}_{\mathbf{t}}^{\mathbf{i}}=\mu_{i}^{V}\left(\nu_{i}^{V}-\mathbf{V}_{\mathbf{t}}^{\mathbf{i}}\right) d t+\varepsilon_{i}^{V} \sqrt{\mathbf{V}_{\mathbf{t}}^{\mathbf{i}}} d W_{i}^{V}(t),
$$
}

with

$$
\mathbb{E}^{Q}\left[d W_{k}^{1}(t) \cdot d W_{j}^{V}(t)\right]= \begin{cases}\rho_{k} d t, & k=j \\ 0, & k \neq j\end{cases}
$$


to a negative NIF slope which indicates that when there is a negative shock in the stochastic volatility factor $i$, there will be a positive shock to the futures returns and vice versa. This will imply a negative return-volatility relation, consequently, an asymmetric volatility reaction. Conversely, a positive $\rho_{i}$ implies a positive relationship between return and conditional volatility, leading to an inverted asymmetric volatility reaction.

Note that, when information up to time $t$ is set at the constant long run volatility $\bar{\sigma}_{i}^{2}$, then (12) derives

$$
\bar{\sigma}_{i}^{2}=\varphi_{i}^{2}(t, T) \mathbf{V}_{\mathbf{t}}^{\mathbf{i}}=\varphi_{i}^{2}(t-1, T) \mathbf{V}_{\mathbf{t}-\mathbf{1}}^{\mathbf{i}}=\ldots
$$

Thus the lagged long run volatility factors $\mathbf{V}_{\mathbf{t}}^{\mathbf{i}}$ are specified by $\bar{V}_{t}^{i}=\bar{\sigma}_{i}^{2} / \varphi_{i}^{2}(t, T)$, for $t \leq T$, i.e. the value of $\bar{\sigma}_{i}^{2}$ and $\varphi_{i}(t, T)$ at time $t$.

The multi-dimensional set up used in the proposed model allows to easily identify and distinguish between the asymmetric volatility factors and the inverted asymmetric volatility factors and measure their contribution. Furthermore, from the following equation

$$
N I F\left(\delta_{1 t}, \ldots, \delta_{n t}\right)=\sum_{i=1}^{n} N I F\left(\delta_{i t}\right),
$$

the overall weighted average effect of these volatility factors can be computed and an aggregate assessment of the return-volatility relation can be obtained. See also Yu (2004) and Yu (2005) for applications of the generalised NIF.

\section{Data and Method}

A database from NYMEX ${ }^{9}$ of futures and futures options for two commodities, gold and crude oil, is used to estimate the stochastic volatility model of Section 3. Gold and crude oil are two of the most liquid commodity markets, whilst they are fundamentally different as gold is classified as an investment commodity, whereas crude oil as a consumption commodity. The gold database covers around 31 years, from 4 October 1982 to 16 April 2012. The crude oil database covers around 21 years, from 2 January 1990 to December 2010, as option price data were available only from 1990. While the database of the gold derivatives market is one

\footnotetext{
${ }^{9}$ The database was purchased from CME Group.
} 
of the longest derivatives databases, crude oil is one of the richest as crude oil is the most active commodity derivatives market.

As the number of available futures contracts over the sample period is very large, for the estimation exercise, futures contracts are selected based on their liquidity. For the options data, the options on the selected futures contracts are considered, but maturities that are more than two years are intentionally avoided. The proposed model assumes non-stochastic interest rates, therefore the option pricing formula for long maturities is not precise. The option prices provided by the CME are American options which are converted to European prices as required for the proposed model, by using the same approach proposed by Broadie, Chernov and Johannes (2007) for equity options and by Trolle and Schwartz (2009) for commodity options. ${ }^{10}$

\subsection{Gold data}

Over the last 31 years, the number of available gold futures contracts with positive open interest per day has increased from 11 on $4^{\text {th }}$ of October 1982 to 22 on $16^{\text {th }}$ of April 2012. In the same period, the maximum maturity of futures contracts with positive open interest has also increased from 690 (calendar) days to 2,078 days.

Based on liquidity, the first three monthly contracts, near to the trade date are initially selected, ${ }^{11}$ followed by the four contracts which have either February, April, June, August, October or December expiration months. Beyond that, liquidity is concentrated in June and December contracts only, hence these four contracts are followed by four semi-annual contracts which have either June or December expiration months. As a result, the total number of futures contracts to be used in our analysis is 69,684 , with the number of contracts to be used on a daily basis varying between 8 and 10. Figure 1.a-Figure 1.c plot the selected futures prices on Wednesdays over the sample period.

From the options data, the options on the first six selected futures contracts are con-

\footnotetext{
${ }^{10}$ The Barone-Adesi and Whaley (1987) formula for American option prices is inverted to obtain lognormal implied volatilities that are subsequently used to compute European Black (1976) prices.

${ }^{11}$ As liquidity is very low for contracts with maturity less than 14 days, so the first contract should have more than 14 days to maturity.
} 


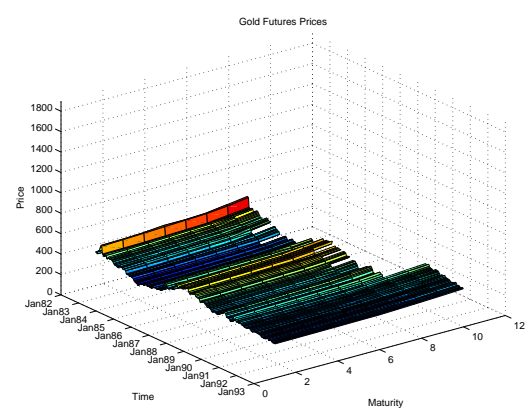

1.a

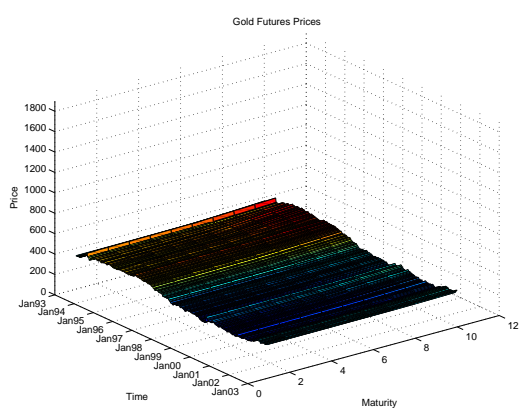

$1 . b$

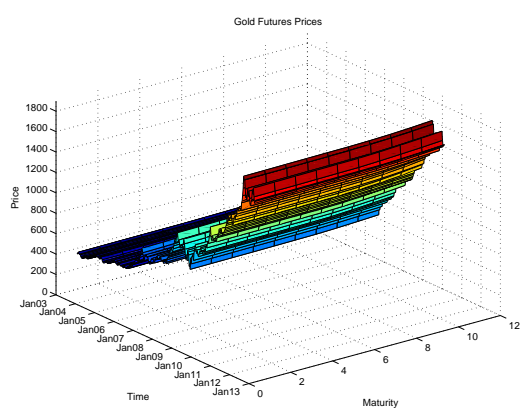

1.c

\section{Figure 1: Gold Futures}

The figure presents futures prices of selected gold futures contracts in three different periods, namely, October 1982 to December 1992, January 1993 to December 2002 and January 2003 to April 2012. The selected contracts are: the first three monthly contracts near to the trade date; the next four contracts which have either February, April, June, August, October or December expiration; and the next four semi-annual contracts (June or December). The data are displayed only on Wednesdays.

sidered, namely the first three monthly contracts and the next three contracts which have either February, April, June, August, October or December expiration months. For each option maturity, six moneyness ${ }^{12}$ intervals have been used, $0.86-0.90,0.91-0.95,0.96-$ 1.00, $1.01-1.05,1.06-1.10,1.11-1.15$. In each moneyness interval, out-of-the-money and at-the-money options that are closest to the interval mean are included. Based on this selection criteria, 367,412 option contracts are considered over the 31 years, with the daily range varying between 19 and 72 contracts (per trading day). Note that the total number of trading days where both futures and options data are available is 7,427 .

\subsection{Crude Oil Data}

In the 21-year crude oil database, the liquidity has consistently increased for all maturities. Based on their liquidity, the first seven monthly contracts, near to the trade date are included, ${ }^{13}$ followed by the three contracts which have either the March, June, September or December expiration months. Beyond that, liquidity is concentrated in December contracts

\footnotetext{
${ }^{12}$ We define as moneyness the ratio of the option strike and the price of the underlying futures contract.

${ }^{13}$ Similarly to the gold futures contracts, the first contract should have more than 14 days to maturity.
} 

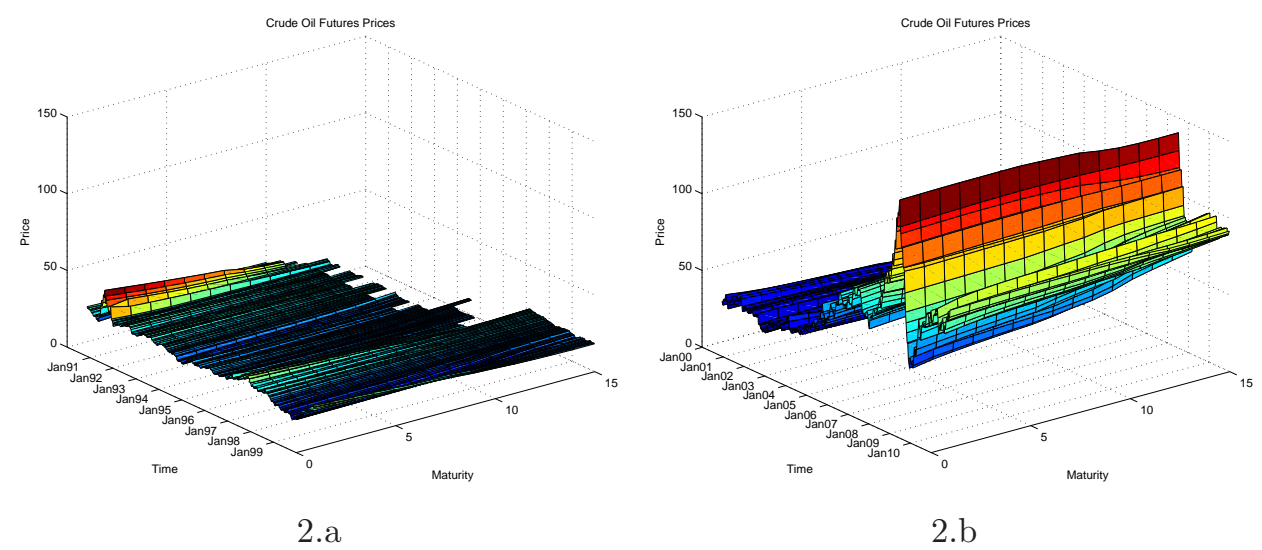

\section{Figure 2: Crude Oil Futures}

The figure presents prices, returns and implied volatilities of selected crude oil futures contracts in two different periods, namely, January 1990 to December 1999 and January 2000 to December 2010. The selected contracts are: the first seven monthly contracts near to the trade date (with the first contract having more than 14 days to maturity); the next three contracts which have either March, June, September or December expiration months; and the next five December contracts. The data are displayed only on Wednesdays.

only, therefore the next five December contracts are included. As a result, the total number of futures contracts to be used in the analysis is 70,735, with the number of contracts to be used on a daily basis varying between 8 and 15. Figure 2.a and Figure 2.b plot the selected futures prices on Wednesdays during the sample periods.

From the crude oil options database, the options on the first ten futures contracts are considered, namely the first seven monthly contracts and the next three quarterly contracts. For each option maturity, six moneyness intervals, $0.86-0.90,0.91-0.95,0.96-1.00,1.01-$ 1.05, $1.06-1.10,1.11-1.15$ are used. In each moneyness interval, out-of-the-money and at-the-money options that are closest to the interval mean are selected. Overall, 433,137 crude oil option contracts are included in the study, with the daily range varying between 29 and 100 contracts (per trading day). Note that the total number of trading days where both futures and options data are available is 5,272.

\subsection{Further model specifications}

The analysis is undertaken by fitting the model to the entire sample, as well as, to subperiods of an approximate length of a decade. As it can be visually detected in Figure 1 
and Figure 2, as well as, from the descriptive statistics displayed in Table 1, over these decades, marked differences in futures price returns and in volatility have occurred in both commodity markets. Noteworthy events such as the gold price crisis in 1990, the Gulf War in 1991 and the GFC in 2008 have influenced the commodity markets and led to extreme market price swings and thus volatility. Moreover, for an analysis of the volatility of the futures commodity markets, it is potentially more informative to concentrate on subperiods as the trading of futures contracts is used to relatively short-lived strategies. ${ }^{14}$

\section{Table 1: Descriptive statistics}

Gold Futures

\begin{tabular}{|c|c|c|c|c|c|c|c|c|}
\hline \multirow[b]{2}{*}{ Maturity } & \multicolumn{2}{|l|}{$1982-1992$} & \multicolumn{2}{|l|}{$1993-2002$} & \multicolumn{2}{|c|}{$2003-2012$} & \multicolumn{2}{|c|}{$1982-2012$} \\
\hline & $1 \mathrm{M}$ & $13 \mathrm{M}$ & $1 \mathrm{M}$ & $13 \mathrm{M}$ & $1 \mathrm{M}$ & $13 \mathrm{M}$ & $1 \mathrm{M}$ & $13 \mathrm{M}$ \\
\hline Mean & -0.000061 & -0.000091 & 0.000027 & 0.000020 & 0.000661 & 0.00066 & 0.000194 & 0.000181 \\
\hline St. Dev. & 0.010674 & 0.010662 & 0.008064 & 0.007884 & 0.012754 & 0.012852 & 0.010623 & 0.010578 \\
\hline Kurtosis & 9.364871 & 9.285527 & 17.842600 & 16.5688 & 6.692487 & 6.682154 & 9.668339 & 9.312701 \\
\hline Skewness & -0.283403 & -0.294973 & 1.064952 & 0.925083 & -0.2806 & -0.30895 & -0.07089 & -0.14321 \\
\hline
\end{tabular}

\begin{tabular}{|c|c|c|c|c|c|c|}
\hline \multirow[b]{3}{*}{ Maturity } & \multicolumn{4}{|c|}{ Crude Oil Futures } & \multirow{2}{*}{\multicolumn{2}{|c|}{$1990-2010$}} \\
\hline & \multicolumn{2}{|l|}{$1990-1999$} & \multicolumn{2}{|l|}{$2000-2010$} & & \\
\hline & $1 \mathrm{M}$ & $13 \mathrm{M}$ & $1 \mathrm{M}$ & $13 \mathrm{M}$ & $1 \mathrm{M}$ & $13 \mathrm{M}$ \\
\hline Mean & 0.000044 & -0.000002 & 0.000471 & -0.000569 & 0.000263 & 0.000294 \\
\hline St. Dev. & 0.024396 & 0.012993 & 0.025635 & 0.017173 & 0.025051 & 0.015327 \\
\hline Kurtosis & 36.4799 & 12.0566 & 7.073648 & 5.603809 & 19.69962 & 7.593329 \\
\hline Skewness & -1.792799 & -0.66896 & -0.203111 & -0.204234 & -0.90038 & -0.32904 \\
\hline
\end{tabular}

The table displays the descriptive statistics for daily log returns of gold futures prices between October 4, 1982 and December 28, 2012 and for daily log returns of crude oil futures prices between January 2, 1990 and April 16, 2010.

\footnotetext{
${ }^{14}$ Nevertheless, for a study on the volatility of the spot commodity markets, it might be more effective to look at the whole period as many investors tend to hold positions on the underlying commodity, especially investment commodities such as gold, over longer periods of time.
} 
For the crude oil market, Bekiros and Diks (2008) point out that the market changes significantly before and after 1999. Given the reduction in OPEC spare capacity and the increase in the US and China's oil consumption and imports, there was an increase in the oil price as well as its volatility. Therefore, the sample is separated into two subsamples, one from 1990-1999, and one from 2000-2010. Table 1 displays the summary statistics for the gold futures market. The middle period is quite different to the other two periods. In the middle period, prices experience much lower volatility with positive skewness and excess kurtosis. However, the gold price crisis in 1990 and the GFC in 2008 amongst other reasons have triggered significant volatility in the gold futures market over the first and the third sample periods, respectively. Consequently, the gold data are examined in three sample periods. ${ }^{15}$

The number of stochastic volatility factors affecting the evolution of the futures curve is initially assessed by performing a principal component analysis (PCA) of futures price returns. According to the PCA results displayed in Table 2, in the gold futures market, one factor can explain on average $98 \%$ of the variations, whereas for the crude oil market, a two-factor model should be used as two factors explain 98\% between 1990 and 1999 and $94 \%$ between 2000 and 2010. As a robustness check, a two-factor stochastic volatility model for gold futures was also considered but the additional factor did not improve the model fit to futures and option prices. In addition for the gold futures market, both hump-shaped and exponentially decaying $\left(\kappa_{i}=0\right)$ specifications were investigated and it was found that the exponentially decaying specifications provide a better fit. ${ }^{16}$ For the crude oil futures market, hump-shaped volatility specifications perform better, as it has been demonstrated in Chiarella et al. (2013). Therefore a one-factor stochastic volatility model with exponentially decaying volatility functions for gold and a two-factor stochastic volatility model with humpshaped volatility functions for crude oil are estimated.

\footnotetext{
${ }^{15}$ The fact that the decades used in the two commodity markets do not completely overlap, does not impair the validity of the results. The key criterion of the analysis is the relative levels of volatility over the different sample periods, thus the break points are not of critical importance.

${ }^{16}$ Results can be provided by the authors upon request.
} 
Table 2: Accumulated percentage of factor contribution

\begin{tabular}{cccc} 
& \multicolumn{3}{c}{ Gold } \\
Time Period & One factor & Two factors & Three factors \\
\hline $1983-1992$ & 0.9815 & 0.9967 & 0.9983 \\
$1993-2002$ & 0.9786 & 0.9946 & 0.9977 \\
$2003-2012$ & 0.9922 & 0.9988 & 0.9998 \\
\hline & & & \\
& & Crude Oil & \\
Time Period & One factor & Two factors & Three factors \\
\hline $1990-1999$ & 0.9042 & 0.9822 & 0.9972 \\
$2000-2010$ & 0.8761 & 0.9402 & 0.9719 \\
\hline
\end{tabular}

The table displays the accumulated percentage of PCA factor contribution to gold futures return variation and crude oil futures return variation. One factor is able to explain most of the variations of the gold futures returns, while at least two factors are required for the crude oil futures returns, during each of the subperiods.

\subsection{Estimation method}

The model is expressed in a state-space mode consisting of the system equations and the observation equations. The system equations describe the discrete evolution of the underlying state-space consisting of the (six) state variables $\mathrm{x}_{i}(t), \mathrm{y}_{i}(t), \mathbf{z}_{i}(t), \phi_{i}(t), \psi_{i}(t)$ and $\mathbf{V}_{\mathbf{t}}{ }^{i}$ with dynamics (under the physical probability measure) driven by the stochastic differential equations (2), (6) and (7). The observation equations relate the observed options and futures prices to the state variables. Specifically, futures prices are exponentially affine in the statespace (as described in (3)) while the options prices are nonlinear functions of the state-space. Therefore an extended Kalman filter is required that applies an approximate linearization of the associated nonlinear observation equations, see Trolle and Schwartz (2009) and Chiarella et al. (2013) for similar applications. The quasi-maximum likelihood estimation algorithm is employed. Appendix B presents the details. The loglikehood function is maximised by using the constrained optimization algorithm e04jy from the NAG library. ${ }^{17}$

\footnotetext{
${ }^{17}$ By using function values only, the quasi-Newton algorithm e04jy finds a minimum or maximum of a continuous function, subject to fixed upper and lower bounds of the independent variables. The e04jy algorithm is available in the NAG toolbox of Matlab.
} 
To tackle the inhomogeneous nature of the model, a time-homogeneous version of the model (3) is assumed where for all $T, F(0, T)=f_{o}$, where $f_{o}$ is a constant representing the long-term futures price (at infinite maturity) and it should also be estimated. To deal with identification, the long run mean of the volatility process $\nu_{i}^{V}$ is normalised to one.

\section{Estimation results}

The parameter estimates of the proposed model are presented next when fitted to gold derivative prices and crude oil derivative prices and the prevailed return-volatility relation is analyzed in terms of possible explanatory factors.

\subsection{Gold futures market}

The parameter estimates of the one-factor stochastic volatility model with exponentially decaying specifications when fitted to gold derivative prices are displayed in Table 3 . The model is estimated over the whole sample period of approximately thirty-one years, as well as over three subperiods representing regimes with different volatility intensity. The performance of the model is adequate with low root mean squared errors (RMSEs) of the percentage differences between actual and fitted gold futures prices as well as of the difference between actual and fitted implied gold option volatilities, as it is displayed in Figure 3.

Substantial differences in the estimates are detected over the three subperiods. The underlying stochastic volatility factor $\mathbf{V}_{\mathbf{t}}$ has a higher mean reversion coefficient $\mu^{V}$ in the middle period (1993-2002) compared to the other two periods. The impact of each stochastic volatility factor on the volatility of the gold futures market is scaled by the function $\varphi(t, T)=\left(\kappa_{0}+\kappa(T-t)\right) e^{-\eta(T-t)}$ (see equation (12)). For all periods, the estimates of the attenuation parameter $\eta$ are small, implying that volatility shocks impact relatively equally along different maturities of the futures contracts. In addition, the correlation coefficients $\rho$ between shocks to the stochastic volatility factors and shocks to the gold futures returns are significantly different from zero and range between $14 \%$ to $23 \%$. The gold futures market volatility is therefore not completely spanned by futures contracts. 


\section{Table 3: Parameter estimates - Gold futures market}

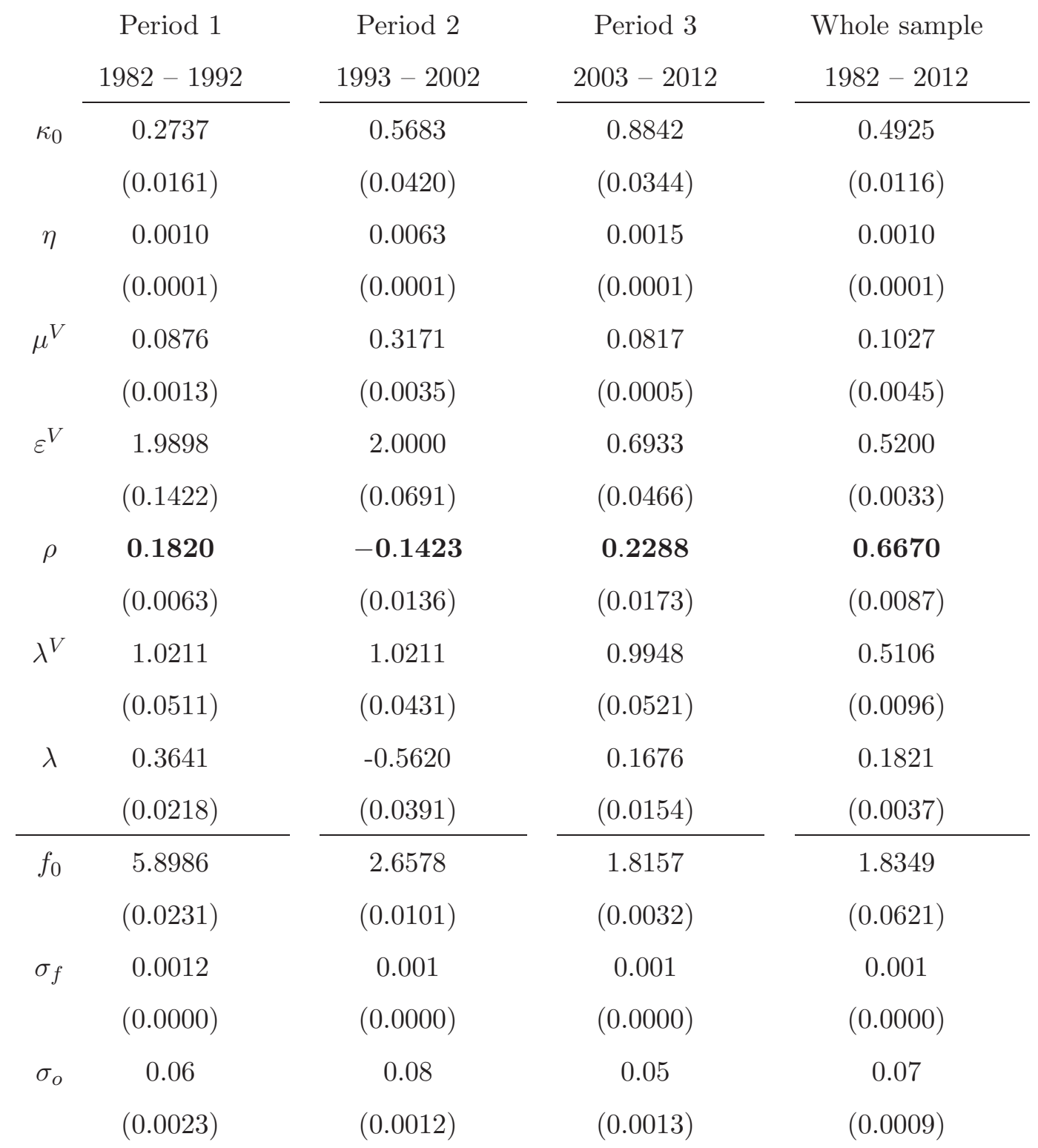

The table displays the maximum likelihood estimates for the one-factor model specifications (the standard errors in parenthesis) over thirty years, in addition to three subperiods, namely; October, 1982 to December, 1992, January 1993 to December 2002 and January 2003 to April 2012. Here $f_{0}$ is the homogenous futures price at time 0 , namely $F(0, T)=f_{0}$, for all $T$. The quantities $\sigma_{f}$ and $\sigma_{o}$ are the standard deviations of the $\log$ futures prices measurements errors and the option price measurement errors, respectively. The long run mean of the volatility process, $\nu^{V}$, has been normalised to one for identification purposes. 

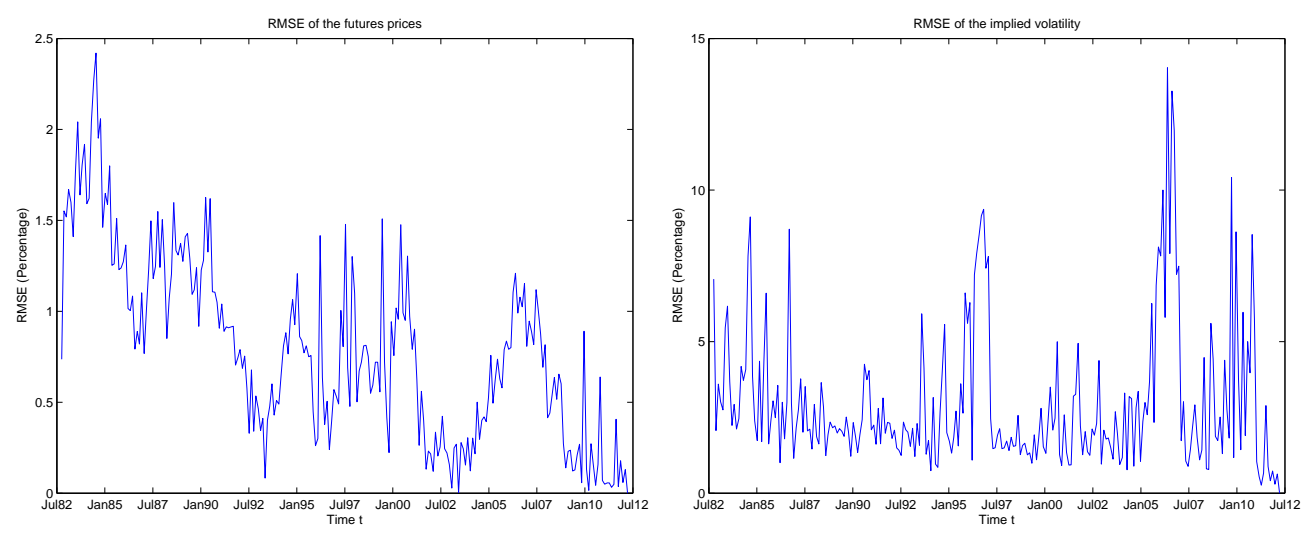

\section{Figure 3: Model goodness of fit - gold futures market}

The figure shows the RMSEs of the percentage differences between actual and fitted gold futures prices (the left-hand panel) as well as of the difference between actual and fitted implied option volatilities (the right-hand panel) for the one-factor model with exponentially decaying volatility. The model is estimated for the whole period from October 1982 to April 2012.

\subsubsection{Return-volatility relation in the gold futures market}

According to the estimation results in Table 3, when the model is fitted to the whole sample, the correlation estimate is positive, implying that in general there is a positive return-volatility relation in the gold futures market. Thus the gold futures volatility for all maturities has a similar response to return shocks as the spot gold volatility, see Baur (2012).

However when the model is estimated over the three subperiods, the responses clearly vary, depending on the level of the volatility. In the less volatile Period 2, the estimated correlation is negative and equal to -0.1423 , while in Period 1 and Period 3 , a positive correlation is observed in both periods. The estimation results confirm the effects discussed in Section 2 regarding the return-volatility relation in investment commodity futures markets such as gold. Period 2 is characterized by low volatility and commodity futures prices are more likely to be principally determined by commodity specific effects. In the case of the gold futures market, as gold is classified as an investment asset like equities, a negative returnvolatility relation should be expected, see Bekaert and Wu (2000) and Dennis et al. (2006). Conversely, in Period 1 and Period 3, the volatility was considerably higher at times. In the equity markets, there is empirical evidence that during high volatility regimes, systematic 
risk factors become more influential, see Dennis et al. (2006). This is also prevalent in the gold futures markets. The positive correlation of 0.182 in the period 1982-1992 and of 0.228 in the period 2003-2012 signify an inverted asymmetric volatility reaction that signals that the safe haven property (a property that is typically instigated by market-wide shock effects) was dominant over these periods.

One noteworthy observation is that the results in Periods 2 and 3 are also consistent with the convenience yield effect. The gold futures market is a market that is typically normal (upward sloping forward curve) thus it should be characterised by a negative returnvolatility relation as it was revealed from our analysis in Period 2. However, during Period 3 and more specifically on 2 December 2008, gold futures market was inverted for the first time in history, augmenting the empirically observed positive return-volatility relation.

Figure 4 displays the NIF over the three subperiods used in our analysis and for four different times to maturity; 0.1, 0.5, 1 and 5 years. First, the NIF is a monotonically decreasing (asymmetric volatility) or an increasing (inverted asymmetric volatility) function. Second, as the time to maturity increases the slope of the NIF remains essentially the same due to the low parameter values for $\eta$ that eliminates the impact of the time to maturity. However, shocks of the same magnitude in the futures returns have a marginally stronger impact to near maturity futures prices compared to longer maturity futures prices. Furthermore, this effect is stronger over the less volatile periods such as the period between January 1993 to January 2003, as shown in Figure 4.b.

\subsection{Crude oil futures market}

The parameter estimates of the two-factor stochastic volatility model with hump-shaped specifications for crude oil futures are displayed in Table 4. Estimation is carried out over the whole sample period of approximately twenty years and over two subperiods. Figure 5 shows the RMSEs of the percentage differences between actual and fitted crude oil futures prices as well as of the difference between actual and fitted implied crude oil option volatilities for the two-factor model with hump-shaped volatility. Generally, the model performs well, except a short period of the post-GFC period.

The crude oil market differs from the gold market in the way volatility changes as time 


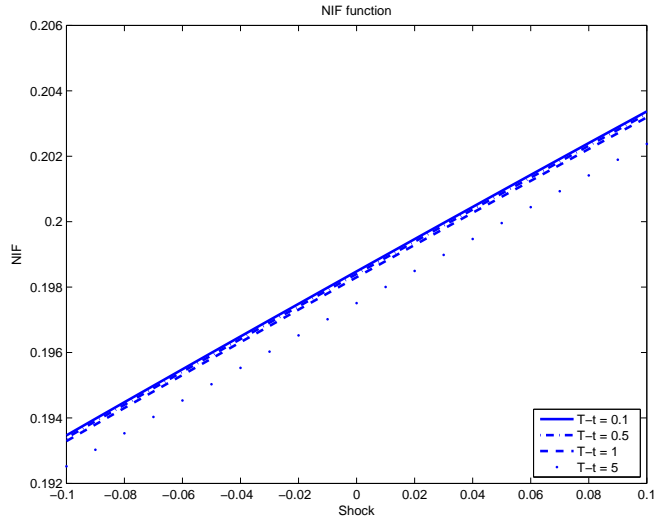

4.a

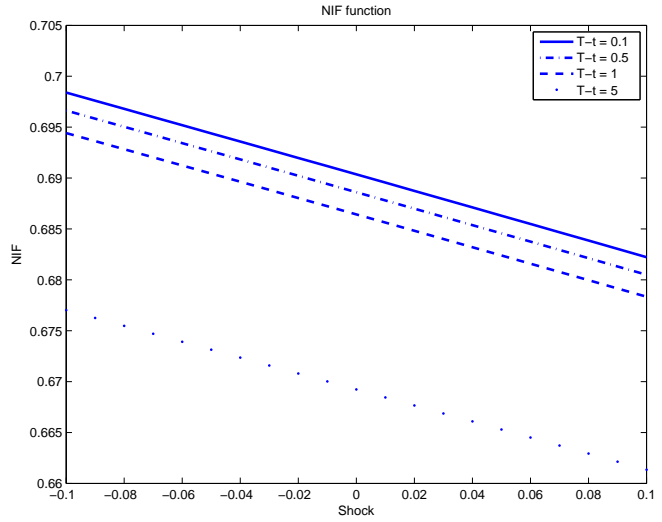

4.b

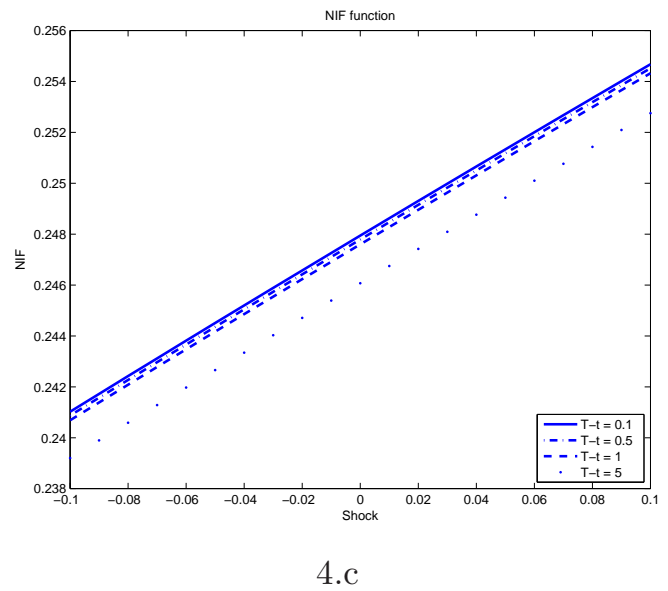

\section{Figure 4: NIF for gold futures market}

The figure compares the NIF for gold futures. Panels 4.a, 4.b, and 4.c present the NIF functions for the three periods, namely, October 1982 to December 1992, January 1993 to December 2002 and January 2003 to April 2012 respectively. For each period, we show the NIF for four different time to maturities; 0.1, 0.5, 1 and 5 years. 
Table 4: Parameter estimates - Crude oil futures market

\begin{tabular}{|c|c|c|c|c|c|c|}
\hline & \multicolumn{2}{|c|}{ Period 1: $1990-1999$} & \multicolumn{2}{|c|}{ Period 2: $2000-2010$} & \multicolumn{2}{|c|}{ Whole sample: 1990 - 2010} \\
\hline & $i=1$ & $i=2$ & $i=1$ & $i=2$ & $i=1$ & $i=2$ \\
\hline \multirow[t]{2}{*}{$\kappa_{0 i}$} & 0.1852 & 1.0374 & 0.0677 & 0.7459 & 0.0010 & 0.7077 \\
\hline & $(0.0116)$ & $(0.0768)$ & $(0.0072)$ & $(0.0316)$ & $(0.0100)$ & $(0.0436)$ \\
\hline \multirow[t]{2}{*}{$\kappa_{i}$} & 1.8370 & 0.0677 & 1.9167 & 0.4010 & 1.8635 & 0.2037 \\
\hline & $(0.0743)$ & $(0.0065)$ & $(0.0684)$ & $(0.0152)$ & $(0.0376)$ & $(0.0082)$ \\
\hline \multirow[t]{2}{*}{$\eta_{i}$} & 1.4754 & 0.0325 & 0.0931 & 0.0890 & 0.5881 & 0.0010 \\
\hline & $(0.0846)$ & $(0.0024)$ & $(0.0050)$ & $(0.0062)$ & $(0.0137)$ & $(0.0022)$ \\
\hline \multirow[t]{2}{*}{$\mu_{i}^{V}$} & 0.0010 & 0.1490 & 0.0010 & 0.0010 & 0.0019 & 0.2379 \\
\hline & $(0.0001)$ & $(0.0057)$ & $(0.0004)$ & $(0.0005)$ & $(0.0003)$ & $(0.0133)$ \\
\hline \multirow[t]{2}{*}{$\varepsilon_{i}^{V}$} & 0.7543 & 1.2690 & 0.5880 & 1.2806 & 0.8513 & 1.4707 \\
\hline & $(0.0352)$ & $(0.0689)$ & $(0.0473)$ & $(0.0871)$ & $(0.0639)$ & $(0.0791)$ \\
\hline \multirow[t]{2}{*}{$\rho_{i}$} & -0.0668 & 0.1225 & -0.0290 & -0.1442 & -0.1606 & -0.1681 \\
\hline & $(0.0042)$ & $(0.0168)$ & $(0.0041)$ & $(0.0109)$ & $(0.0105)$ & $(0.0096)$ \\
\hline \multirow[t]{2}{*}{$\lambda_{i}^{V}$} & -0.9521 & 1.0619 & 0.9974 & 1.0423 & -0.9574 & 1.1939 \\
\hline & $(0.0721)$ & $(0.0678)$ & $(0.0351)$ & $(0.0645)$ & $(0.0532)$ & $(0.0825)$ \\
\hline \multirow[t]{2}{*}{$\lambda_{i}$} & 0.6349 & 1.0227 & 0.7424 & 1.0227 & 0.1844 & 1.0227 \\
\hline & $(0.0328)$ & $(0.0637)$ & $(0.0449)$ & $(0.0623)$ & $(0.0050)$ & $(0.0661)$ \\
\hline \multirow[t]{2}{*}{$f_{0}$} & 2.0099 & & 1.9530 & & 1.9513 & \\
\hline & $(0.0132)$ & & $(0.0211)$ & & $(0.0257)$ & \\
\hline \multirow[t]{2}{*}{$\sigma_{f}$} & 0.0010 & & 0.0010 & & 0.0010 & \\
\hline & $(0.0000)$ & & $(0.0000)$ & & $(0.0000)$ & \\
\hline \multirow[t]{2}{*}{$\sigma_{o}$} & 0.0100 & & 0.1070 & & 0.0377 & \\
\hline & $(0.0021)$ & & $(0.0053)$ & & $(0.0015)$ & \\
\hline
\end{tabular}

The table displays the maximum-likelihood estimates for the hump-shaped two-factor stochastic volatility model specifications and the standard errors in parenthesis for twenty years as well as for two ten-year subperiods, namely, January, 1990 to December, 1999, January 2000 to December 2010. Here $f_{0}$ is the homogenous futures price at time 0 , namely $F(0, T)=f_{0}$, for all $T$. The quantities $\sigma_{f}$ and $\sigma_{o}$ are the standard deviations of the log futures prices measurements errors and the option price measurement errors, respectively. We normalized the long run mean of the volatility process, $\nu_{i}^{V}$, to one to achieve identification. 

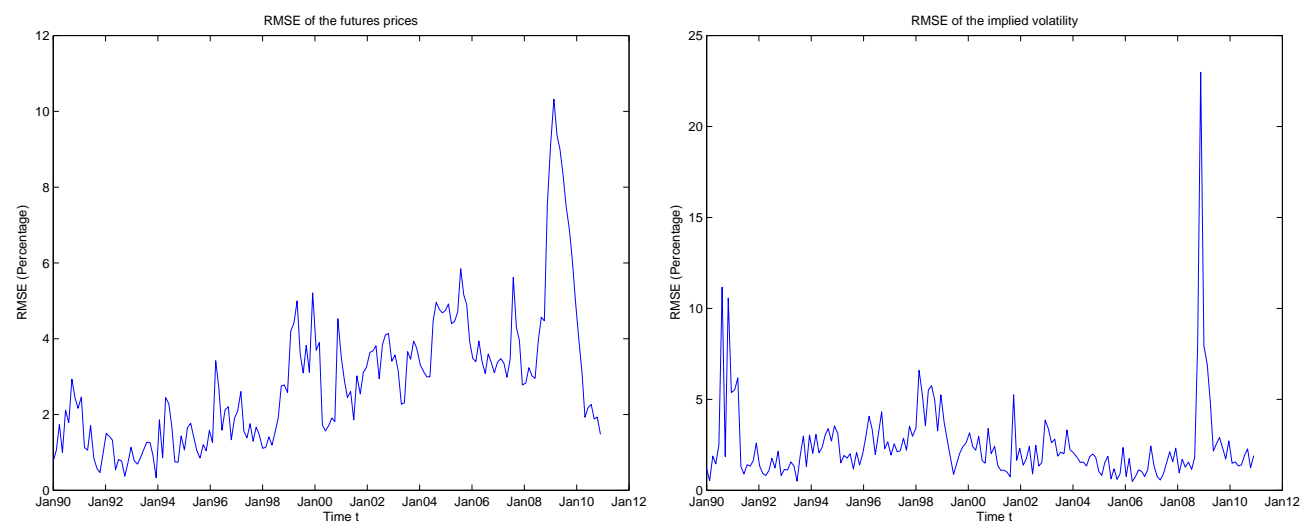

\section{Figure 5: Model goodness of fit - crude oil futures market}

The figure shows the RMSEs of the percentage differences between actual and fitted crude oil futures prices (the left-hand panel) as well as of the difference between actual and fitted implied option volatilities (the right-hand panel) for the two-factor model with hump-shaped volatility. The model is estimated for the whole period from January 1990 to December 2010.

to maturity changes. In the gold market, the effect dies out (though very slowly) as the time to maturity increases. In the crude oil market, the significant estimates of $\kappa_{i}$ confirm the existence of hump-shaped volatility. Similar to the gold market, the volatility of the crude oil market is not completely spanned by futures contracts. The correlation coefficient $\rho$ between shocks to the stochastic volatility factors and shocks to the crude oil futures returns vary in magnitude from $3 \%$ to $15 \%$. Furthermore, the low value of $\mu_{i}^{V}$ suggest that the volatility factors are highly persistent, results that are consistent with findings by Cunado, Gil-Alana and Perez-De-Gracia (2010).

\subsubsection{Return-volatility relation in the crude oil futures market}

When the model is fitted to the whole sample, the estimated correlations between futures returns and innovations in the volatility for the two factors capturing the evolution of the volatility structure are -0.1606 and -0.1681 , respectively. These negative correlations suggest a negative return-volatility relation, which is a similar response as in the spot crude oil market. Hassan (2011) and Salisu and Fasanya (2013) found that the leverage effects postulate asymmetric volatility in crude oil markets. This is also a typical response in the equity markets, essentially implying that negative returns in the crude oil futures market 
would potentially increase volatility in the oil futures price more than positive returns do.

Table 5: Contribution of volatility factors

\begin{tabular}{cccccc} 
& \multicolumn{2}{c}{$1990-1999$} & & \multicolumn{2}{c}{$2000-2010$} \\
& Contribution & Return-Vol relation & & Contribution & Return-Vol relation \\
\cline { 2 - 3 } \cline { 5 - 6 }$\sigma_{1}$ & $34.97 \%$ & negative & & $64.48 \%$ & negative \\
$\sigma_{2}$ & $65.03 \%$ & positive & & $35.52 \%$ & negative \\
\hline
\end{tabular}

The table reports the contribution of each volatility factor to the total variance of the crude oil futures price returns for the two-factor model.

A more thorough analysis over the two subsamples though reveals that there is more to the crude oil futures return-volatility relation. The descriptive statistics on Table 1 suggest that Period 2 (2000-2010) is far more volatile compared to Period 1 (1990-1999), especially around the 2003 Gulf War and the GFC in 2008. In the less volatile Period 1, the connection between inventories and volatility, as explained by the Theory of Storage and more specifically the inventory effect, justifies a positive return-volatility relation, as discussed in Section 2.2. Furthermore in Period 1, the crude oil futures market was mostly inverted $\left(77.39 \%\right.$ of the time in weak backwardation $\left.{ }^{18}\right)$ that consequently implied a high convenience yield. Thus the positive correlation estimate $(0.1225)$ for one of the volatility factors also verifies the argument that inverted commodity markets give rise to a positive return-volatility relation, as the convenience yield effect suggests in Section 2.

Building on the results by Dennis et al. (2006) and Elder, Miao and Ramchander (2012), it is assumed that volatility can be decomposed into two main components (similarly to returns); one component could be postulated by systematic market-wide shocks, while the other component could be controlled by commodity specific shocks. Table 5 displays the relative contribution of each volatility factor to the total volatility, and the type of volatility reaction. Accordingly, the dominant factor that accounts for $65 \%$ of the market variation is

\footnotetext{
${ }^{18}$ Weak backwardation is defined as the case of "discounted" futures prices being below spot commodity prices. We have computed the percentage of weak backwardation for the 13-month futures contracts.
} 
the positively correlated volatility factor. This finding supports the Dennis et al. (2006) notion asserting that when the market is quiet then commodity specific shock effects dominate such as inventory. On the contrary, the second (less-contributing) volatility factor displays a negative correlation of -0.0668 indicating an asymmetric volatility reaction and potentially captures the impact of other market related shocks.

In the more volatile Period 2, the correlation estimates for the two volatility factors are both negative implying a negative return-volatility relation for both factors, a reaction that has been explained by the leverage effect, see Salisu and Fasanya (2013). Taking into account also the contribution of each factor to the total variance, see Table 5 , the more dominant factor with a contribution of $64.48 \%$ displays a correlation of -0.0290 , while the other factor has a correlation of -0.1442 . Thus the dominant volatility factor has an inverse reaction compared to the Period 1, a reaction that the convenience yield effect can also account for. The crude oil market was normal for over four years and these correlation estimates support our notion of the convenience yield effect claiming that normal commodity markets should yield a positive return-volatility relation. ${ }^{19}$ Additionally, it is apparent that this extended period of normal market conditions (in the crude oil futures market that is traditionally inverted) was triggered primarily by the significant market-wide shocks that the crude oil market experienced over this period such as GFC, global economic contraction and currency depreciation/appreciation. Thus, when market uncertainty is high, market-wide shock effects dominate which is consistent with Dennis et al. (2006) conclusions in equity markets.

The NIF for the crude oil futures market is a surface, rather than a line as in the gold futures market, due to the use of two volatility factors, see Figure 6 . In the second period, namely 2000-2010, both volatility factors have negative correlation with shocks to the futures returns, therefore the NIF surface clearly tilts down as volatility shocks increase. Even

\footnotetext{
${ }^{19}$ The magnitude of the correlation of this volatility factor is marginally negative probably due to the fact that we fit the model into a ten-year dataset and the market was normal for only four years. When the model was fitted into the 5-year dataset from 2006 to 2010 where the market was mostly normal then the correlations are -0.2130 and -0.0614 respectively. The results are not presented here for the sake of saving space but they are available upon request.
} 

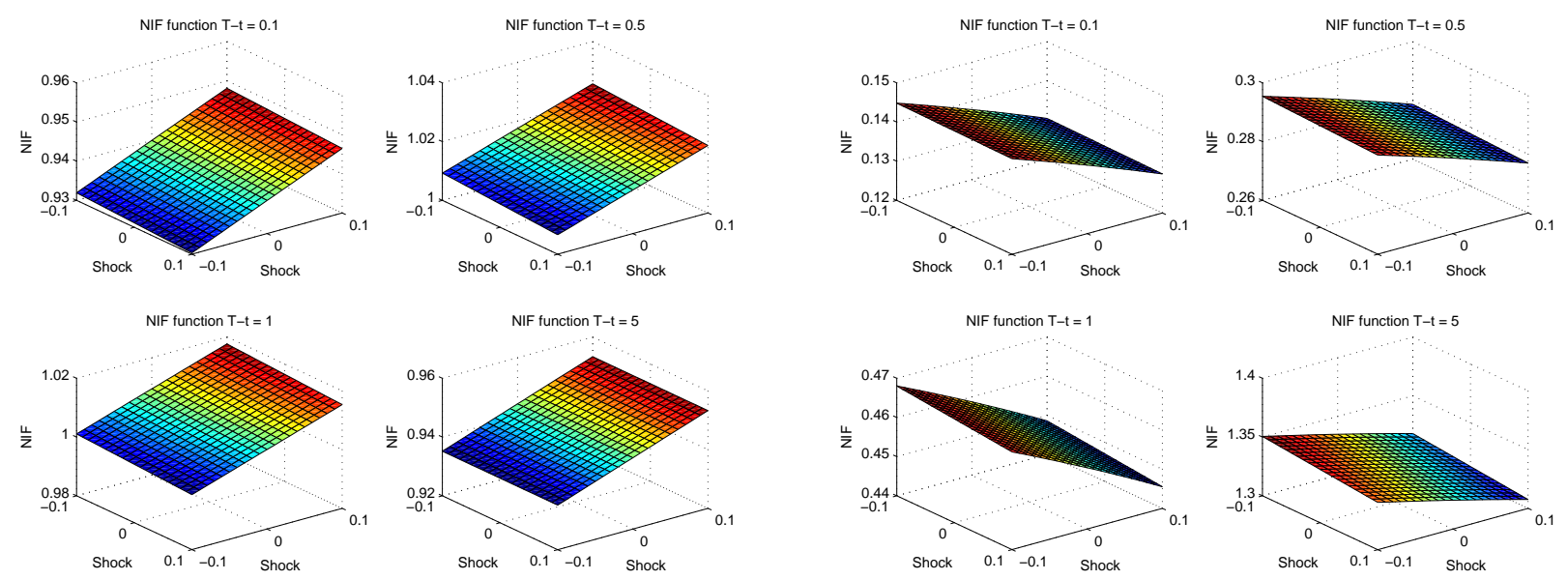

$6 . \mathrm{a}$
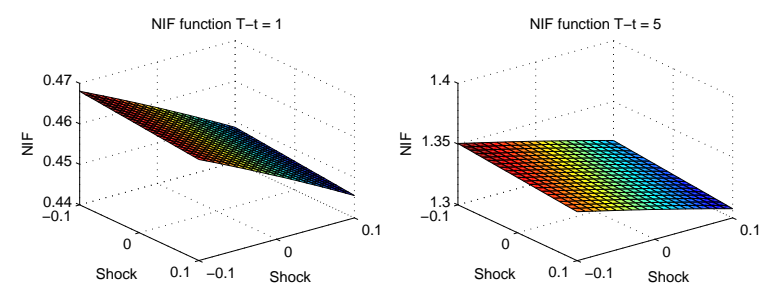

$6 . \mathrm{b}$

\section{Figure 6: NIF for crude oil futures market}

Panel 6.a is for the first period 1990 - 1999, while Panel 6.b is for the second period $2000-2010$

though the volatility factors are hump-shaped, the hump for both factors is beyond five years time to maturity. As a result, in the practical range of futures contract volatility, it is observed a monotonic increase in volatility impact (when there is a shock in the futures market) as the time to maturity increases. In Period 1, on the other hand, only the hump for the first volatility is beyond 5 years, whereas the hump for the second volatility is around 5 months. The two volatility factors have an opposite relationship with the shocks to futures return (negative $\rho_{1}$ and positive $\rho_{2}$ ), however, the second volatility factor is stronger than the first one (see Table 6), resulting in an upward sloping aggregate NIF.

\subsection{Skewness of futures returns}

The ability of the futures price volatility skewness to relate to the return-volatility relation in the two commodity futures markets is also assessed. Table 1 presents the descriptive statistics for one-month and thirteen-month gold futures prices and crude oil futures prices. Generally over volatile market conditions, a negative skewness has been detected in the commodity (spot and futures) markets. This negative skewness is also evident in equity markets and has been linked to their asymmetric volatility feature, (Harvey and Siddique (2000)). Two noteworthy observations can be made in the commodity futures markets; (a) high volatility in the gold futures market is related to a negative skewness of the gold futures 
returns, while low volatility is related to a positive skewness of the gold futures returns and (b) high volatility in the crude oil futures market is related to a negative skewness of the crude oil futures returns, while low volatility is related to a more negative skewness. During volatile periods, the convenience yield effect linked to futures market conditions (normal or inverted) is critical in explaining the negative return-volatility relation in the crude oil futures market, while the safe haven property of gold prices can explain the positive returnvolatility relation in the gold futures market. However, under low volatility regimes, their importance becomes secondary as does their link to the asymmetric behavior of volatility. ${ }^{20}$ Under stable market conditions, gold traders, acting as rational investors, tend to prefer positive return feedbacks (more than the negative ones) while crude oil traders respond with more negative return feedbacks than positive ones. A tentative explanation is that under stable market conditions, the contribution of the convenience yield increases, causing crude oil futures prices to drop, thus more negative futures return feedbacks are more likely to occur rather than positive ones.

\section{Conclusion}

This paper examines the relation between futures returns and volatility changes in two major commodity futures markets, gold and crude oil. By using an extensive database on futures and options, a continuous time stochastic volatility model is estimated. The correlation structure between the futures returns and the innovations of its volatility gauges the nature of the futures return-volatility relation.

The empirical investigations have led to four main findings regarding the return-volatility relation in futures markets. First, the proposed model is consistent with results from existing literature that claims that the gold volatility is inverted asymmetric, mostly due to safe haven property and the crude oil futures volatility is asymmetric, due to the volatility feedback effect and/or the leverage effect. Nevertheless, the approach used in the paper is different to prior research in two respects, a) a continuous time stochastic volatility model is used while

\footnotetext{
${ }^{20} \mathrm{Wu}(2001)$ empirically demonstrated that over stable market conditions the volatility feedback effect has a secondary role on explaining volatility asymmetry in equity markets.
} 
most literature employs GARCH type models and b) it is demonstrated that this relation holds similarly in the commodity futures markets, rather than the spot commodity markets to which most literature is dedicated.

Second, a new effect has been proposed, namely the convenience yield effect, that links the state of the commodity futures market (normal or inverted) to the return-volatility relation (negative or positive). More specifically, as convenience yield increases (decreases) implying that the commodity futures market become inverted (normal), then the increasing volatility associated with the effects that impact on the convenience yield will lead to increasing (decreasing) futures returns. Thus inverted (normal) commodity futures markets incite a positive (negative) return-volatility relation. This effect becomes an important factor in explaining the futures return-volatility relation, especially for crude oil.

Third, the intensity of the volatility also plays an important role as the reaction over periods of low volatility is typically different to the reaction over periods of high volatility in both the gold and the crude oil futures markets. Over quiet periods, a negative returnvolatility relation is prevailed in the gold futures market, while during volatile periods where market-wide effects dominate, a positive relation is present. Thus, tail events are very important determinants of the return-volatility relation in the commodity futures markets.

Fourth, the model allows for several volatility factors, each one of which can potentially capture different volatility effects. Indeed for crude oil, the two driving volatility factors have different reactions. In a low volatility regime, the most contributing volatility factor holds a positive relation with returns as the convenience yield effect claims (crude oil futures market was predominantly inverted), while the less contributing volatility factor holds a negative relation potentially due to the volatility feedback effect. However in a high volatility regime, the most contributing volatility factor holds a negative relation due to the convenience yield effect (as crude oil futures market was mainly normal).

These findings are of critical importance for practical applications related to trading and pricing derivatives and play an important role in investment management and risk management. This paper, by employing an alternative approach via continuous time stochastic volatility models, has successfully captured stylised facts about the return-volatility relation in the crude oil futures market and the gold futures market. The results induce the pursuit of 
a sophisticated economic analysis to statistically test the results in terms of specifying true break points for volatility and exploring the direct impact of commodity-specific effects such as inventories or market-wide shocks, such as investment growth, in the return-volatility relation. This type of economic analysis is beyond the purpose of the current study.

\section{Appendix A. The European Option Pricing Equations}

The price at time $t$ of a European put option with strike $K$ and maturity $T_{o}$ on a futures contract with maturity $T$, is expressed as

$$
\begin{aligned}
\mathcal{P}\left(t, T_{o}, T, K\right) & =\mathbb{E}_{t}^{Q}\left[e^{-\int_{t}^{T_{o}} r_{s} d s}\left(K-F\left(T_{o}, T, \mathbf{V}_{\mathbf{T}_{\mathbf{o}}}\right)\right)^{+}\right] \\
& =P\left(t, T_{o}\right)\left[K G_{0,1}(\log (K))-G_{1,1}(\log (K))\right]
\end{aligned}
$$

where

$$
G_{a, b}(y)=\frac{\phi\left(t ; a, T_{o}, T\right)}{2}-\frac{1}{\pi} \int_{0}^{\infty} \frac{\operatorname{Im}\left[\phi\left(t ; a+\mathbf{i} b u, T_{o}, T\right) e^{-\mathbf{i} u y}\right]}{u} d u,
$$

and $P\left(t, T_{o}\right)$ is the price at time $t$ of a zero-coupon bond with maturity $T_{o}$. Note that $\mathbf{i}^{2}=-1$ and for $t \leq T_{o} \leq T$, the characteristic function $\phi\left(t ; v, T_{o}, T\right)=: \mathbb{E}_{t}^{Q}\left[\exp \left\{v \ln F\left(T_{o}, T, \mathbf{V}_{\mathbf{T}_{\mathbf{o}}}\right)\right\}\right]$ is expressed as

$$
\phi\left(t ; v, T_{o}, T\right)=\exp \left\{M\left(t ; v, T_{o}\right)+\sum_{i=1}^{n} N_{i}\left(t ; v, T_{o}\right) \mathbf{V}_{\mathbf{t}}{ }^{i}+v \ln F\left(t, T, \mathbf{V}_{\mathbf{t}}\right)\right\} .
$$

$M(t)=M\left(t ; v, T_{o}\right)$ and $N_{i}(t)=N_{i}\left(t ; v, T_{o}\right)$ (for $\left.i=1, \ldots, n,\right)$ satisfy the Ricatti ordinary differential equations

$$
\begin{aligned}
& \frac{d M(t)}{d t}=-\sum_{i=1}^{n} \mu_{i}^{V} \nu_{i}^{V} N_{i}(t), \\
& \frac{d N_{i}(t)}{d t}=-\frac{v^{2}-v}{2}\left(\varphi_{i}\right)^{2}-\left(\varepsilon_{i}^{V} v \rho_{i} \varphi_{i}-\mu_{i}^{V}\right) N_{i}(t)-\frac{1}{2} \varepsilon_{i}^{V^{2}} N_{i}^{2}(t),
\end{aligned}
$$

subject to the terminal conditions $M\left(T_{o}\right)=N_{i}\left(T_{o}\right)=0$, where $\varphi_{i}=\left(\kappa_{0 i}+\kappa_{i}(T-t)\right) e^{-\eta_{i}(T-t)}$.

\section{Appendix B. The Extended Kalman Filter}

The system equation describing the dynamics of the six state variables of the proposed model is expressed as

$$
X_{t+1}=\Phi_{0}+\Phi_{X} X_{t}+w_{t+1}, w_{t+1} \sim \operatorname{iid} N\left(0, Q_{t}\right),
$$


where $X_{t}=\left(\mathrm{x}_{i}(t), \mathrm{y}_{i}(t), \mathrm{z}_{i}(t), \phi_{i}(t), \psi_{i}(t), \mathbf{V}_{\mathbf{t}}{ }^{i}\right)$ are driven by the stochastic differential equations (2), (6) and (7). The observation equation that links the state variables with the market-observable variables (in our case futures prices and options prices) is of the form

$$
z_{t}=h\left(X_{t}\right)+u_{t} u_{t} \sim \operatorname{iid} N(0, \Omega)
$$

Note that, the $h$ function is nonlinear due to the nonlinear functional forms of the option prices, see (A.1) and (A.2). Let $\hat{X}_{t}=\mathbb{E}_{t}\left[X_{t}\right]$ and $\hat{X}_{t \mid t-1}=\mathbb{E}_{t-1}\left[X_{t}\right]$ denote the expectations of $X_{t}$ at $t$ and $t-1$ respectively and let $\mathcal{C}_{t}$ and $\mathcal{C}_{t \mid t-1}$ denote the corresponding estimation error covariance matrices. The $h$ function is linearized around $\hat{X}_{t \mid t-1}$, as

$$
z_{t}=\left(h\left(\hat{X}_{t \mid t-1}\right)-H_{t}^{\prime} \hat{X}_{t \mid t-1}\right)+H_{t}^{\prime} X_{t}+u_{t}, u_{t} \sim \operatorname{iid} N(0, \Omega),
$$

where

$$
H_{t}^{\prime}=\left.\frac{\partial h\left(X_{t}\right)}{\partial X_{t}^{\prime}}\right|_{X_{t}=\hat{X}_{t \mid t-1}}
$$

Then the Kalman filter yields

$$
\begin{aligned}
\hat{X}_{t+1 \mid t} & =\Phi_{0}+\Phi_{X} \hat{X}_{t} \\
\mathcal{C}_{t+1 \mid t} & =\Phi_{X} \mathcal{C}_{t} \Phi_{X}^{\prime}+Q_{t}
\end{aligned}
$$

and

$$
\begin{aligned}
\hat{X}_{t+1} & =\hat{X}_{t+1 \mid t}+\mathcal{C}_{t+1 \mid t} H_{t}^{\prime} F_{t}^{-1} \epsilon_{t} \\
\mathcal{C}_{t+1} & =\mathcal{C}_{t+1 \mid t}-\mathcal{C}_{t+1 \mid t} H_{t}^{\prime} F_{t}^{-1} H_{t} \mathcal{C}_{t+1 \mid t}
\end{aligned}
$$

with

$$
\begin{aligned}
\epsilon_{t} & =z_{t+1}-h\left(\hat{X}_{t+1 \mid t}\right), \\
F_{t} & =H_{t} \mathcal{C}_{t+1 \mid t} H_{t}^{\prime}+\Omega .
\end{aligned}
$$

Finally, the log-likelihood function is constructed as

$$
\log L=-\frac{1}{2} \log (2 \pi) \sum_{t=1}^{T} N_{t}-\frac{1}{2} \sum_{t=1}^{T} \log \left|F_{t}\right|-\frac{1}{2} \sum_{t=1}^{T} \epsilon_{t}^{\prime} F_{t}^{-1} \epsilon_{t} .
$$




\section{References}

Barone-Adesi, G. and Whaley, R. (1987), 'Efficient analytic approximation of American option values', Journal of Finance 42, 301-320.

Baur, D. G. (2012), 'Asymmetric volatility in the gold market', The Journal of Alternative Investments 14(4), 26-38.

Baur, D. G. and McDermott, T. K. (2010), 'Is gold a safe haven? International evidence', Journal of Banking and Finance 34, 1886-1898.

Bekaert, G. and Wu, G. (2000), 'Asymmetric volatility and risk in equity markets', The Review of Financial Studies 13(1), 1-42.

Bekiros, S. D. and Diks, C. G. H. (2008), 'The relationship between crude oil spot and futures prices: Cointegration, linear and nonlinear causality', Energy Economics 30, 2673-2685.

Björk, T., Landén, C. and Svensson, L. (2004), 'Finite dimensional markovian realizations for stochastic volatility forward rate models', Proceedings of the Royal Society 460(Series A), 53-83.

Black, F. (1976), 'The pricing of commodity contracts', Journal of Financial Economics 3(1-2), 167179.

Black, F. (1976b), Studies in stock price volatility changes, in 'Proceedings of the 1976 Business Meeting of the Business and Economic Statistics Section, American Statistical Association', pp. $177-181$.

Broadie, M., Chernov, M. and Johannes, M. S. (2007), 'Understanding index option returns', Review of Financial Studies 22(11), 4493-4529.

Campbell, J. Y. and Hentschel, L. (1992), 'No news is good news: An asymmetric model of changing volatility in stock returns', Journal of Financial Economics 31, 281-318.

Carpantier, J. F. and Dufays, A. (2013), 'Commodity Inventory Effect', University of Luxembourg, CREA Discussion Papers, 2013-07.

Carpantier, J. F. and Samkharadze, B. (2013), 'The Asymmetric Commodity Inventory Effect on the Optimal Hedge Ratio', The Journal of Futures Markets 33(9), 868-888. 
Chiarella, C., Kang, B., Nikitopoulos, C. S. and Tô, T. (2013), 'Humps in the volatility structure of the crude oil futures market: New evidence', Energy Economics 40, 989-1000.

Chiarella, C. and Kwon, O. K. (2003), 'Finite Dimensional Affine Realisations of HJM Models in Terms of Forward Rates and Yields', Review of Derivatives Research 6(2), 129-155.

Collin-Dufresne, P. and Goldstein, R. S. (2002), 'Do bonds span the fixed income markets? Theory and evidence for unspanned stochastic volatility', Journal of Finance 57(4), 1685-1730.

Cootner, P. H. (1960), 'Returns to speculators: Telser vs. Keynes', Journal of Political Economy 68, 396-404.

Cunado, J., Gil-Alana, L. and Perez-De-Gracia, F. (2010), 'Persistence in Some Energy Futures Markets', Journal of Futures Markets 30(5), 490-507.

Dai, Q. and Singleton, K. J. (2000), 'Specification analysis of affine term structure models', Journal of Finance 55(5), 1943-1978.

Dennis, P., Mayhew, S. and Stivers, C. (2006), 'Stock returns, implied volatility innovations, and the asymmetric volatility phenomenon', Journal of Financial and Quantitative Analysis 41(2), 381406.

Doran, J. S. and Ronn, E. I. (2008), 'Computing the market price of volatility risk in the energy commodity market', Journal of Banking and Finance 32, 2541-2552.

Duffie, D. (2001), Dynamic asset pricing theory, Princeton, NJ:Princeton University Press.

Duffie, D., Pan, J. and Singleton, K. (2000), 'Transform analysis and asset pricing for affine jumpdiffusions', Econometrica 68(6), 1343-1376.

Elder, J., Miao, H. and Ramchander, S. (2012), 'Impact of macroeconomic news on metal futures', Journal of Banking and Finance 36, 51-65.

Engle, R. and Ng, V. (1993), 'Measuring and testing the impact of news in volatility', Journal of Finance 43, 1749-1778.

Geman, H. and Ohana, S. (2009), 'Forward curves, scarcity and price volatility in oil and natural gas markets', Energy Economics 31(4), 576-585. 
Giamouridis, D. G. and Tamvakis, M. N. (2001), 'The relation between return and volatility in the commodity markets', Journal of Alternative Investments 4(1), 54-62.

Glosten, L. R., Jagannathan, R. and Runkle, D. E. (1993), 'On the relation between the expected value and the volatility of the nominal excess return on stocks', Journal of Finance 48, 1779-1801.

Gorton, G. B., Hayashi, F. and Rouwenhorst, K. G. (2013), 'The fundamentals of commodity futures returns', Review of Finance 17(1), 35-105.

Hamilton, J. D. and Wu, J. (2014), 'Risk premia in crude oil futures prices', Journal of International Money and Finance 42(C), 9-37.

Harvey, C. and Siddique, A. (2000), 'Conditional skewness in asset pricing tests', Journal of Finance $\mathbf{5 5 ( 3 ) , ~} 12631296$.

Hassan, S. A. (2011), 'Modelling asymmetric volatility in oil prices', Journal of Applied Business Research 27(3), 7178.

Heath, D., Jarrow, R. and Morton, A. (1992), 'Bond pricing and the term structure of interest rates: A new methodology for contingent claims valuation', Econometrica 60(1), 77-105.

Hibbert, A. M., Daigler, R. T. and Dupoyet, B. (2008), 'A behavioral explanation for the negative asymmetric return-volatility relation', Journal of Banking and Finance 32, 2254-2266.

Kaldor, N. (1939), 'Speculation and economic stability', Review of Economic Studies 7, 1-27.

Kilian, L. (2009), 'Not all oil price shocks are alike: Disentangling demand and supply shocks in the crude oil market', American Economic Review 99, 1053-1069.

Kilian, L. and Hicks, B. (2013), 'Did unexpected strong economic growth caused the oil shock of 2003-2008?', Journal of Forecasting 32(5), 385-394.

Morana, C. (2013), 'Oil price dynamics, macro-finance interactions and the role of financial speculation', Journal of Banking and Finance 37, 206-226.

Ng, V. K. and Pirrong, S. C. (1994), 'Fundamentals and Volatility: Storage, Spreads, and the Dynamics of Metals Prices', Journal of Business 67(2), 203-230. 
Pindyck, R. (2001), 'The dynamics of commodity spot and futures markets: A primer', The Energy Journal 22(3), 1-16.

Reboredo, J. C. (2013), 'Is gold a safe haven or a hedge for the US dollar? Implications for risk management', Journal of Banking and Finance 37, 2665-2676.

Salisu, A. and Fasanya, I. (2013), 'Modelling oil price volatility with structural breaks', Energy Policy 52(C), 554-562.

Tokic, D. (2010), 'The 2008 oil bubble: Causes and consequences', Energy Policy 38, 6009-6015.

Trolle, A. B. and Schwartz, E. (2009), 'Unspanned stochastic volatility and the pricing of commodity derivatives', Review of Financial Studies 22(11), 4423-4461.

Tully, E. and Lucey, B. M. (2007), 'A power GARCH examination of the gold market', Research in International Business and Finance 21(2), 316-325.

Wu, G. (2001), 'The determinants of asymmetric volatility', The Review of Financial Studies 14(3), 837-859.

Yu, J. (2004), 'Asymmetric responce of volatility: Evidence from stochastic volatility models and realised volatility', Research Collection School of Economics (Open Access), Paper 820 .

Yu, J. (2005), 'On Leverage in a Stochastic Volatility Model', Journal of Econometrics 127, 165178. 